\title{
Utilization of orange peel, a food industrial waste, in the production of exo-polygalacturonase by pellet forming Aspergillus sojae
}

\author{
Ali Oguz Buyukkileci • Marcello Fernandez Lahore • \\ Canan Tari
}

Received: 23 September 2014/ Accepted: 19 October 2014/Published online: 29 October 2014

(C) Springer-Verlag Berlin Heidelberg 2014

\begin{abstract}
The production of exo-polygalacturonase (exo$\mathrm{PG}$ ) from orange peel (OP), a food industrial waste, using Aspergillus sojae was studied in submerged culture. A simple, low-cost, industrially significant medium formulation, composed of only $\mathrm{OP}$ and $\left(\mathrm{NH}_{4}\right)_{2} \mathrm{SO}_{4}$ (AS) was developed. At an inoculum size of $2.8 \times 10^{3}$ spores $/ \mathrm{mL}$, growth was in the form of pellets, which provided better mixing of the culture broth and higher exo-PG activity. These pellets were successfully used as an inoculum for bioreactors and $173.0 \mathrm{U} / \mathrm{mL}$ exo-PG was produced. Fed-batch cultivation further enhanced the exo-PG activity to $244.0 \mathrm{U} / \mathrm{mL}$ in $127.5 \mathrm{~h}$. The final morphology in the form of pellets is significant to industrial fermentation easing the subsequent downstream processing. Furthermore, the low $\mathrm{pH}$ trend obtained during this fermentation serves an advantage to fungal fermentations prone to contamination problems. As a result, an economical exo-PG production process was defined utilizing a food industrial byproduct and producing high amount of enzyme.
\end{abstract}

Keywords Exo-polygalacturonase $\cdot$ Aspergillus sojae . Food industry waste $\cdot$ Orange peel $\cdot$ Low-cost medium

\section{Introduction}

Citrus peel, which constitutes $50 \%$ of fresh fruit weight, is the main by-product of citrus processing fruit juice

\footnotetext{
A. O. Buyukkileci · C. Tari $(\square)$

Department of Food Engineering, İzmir Institute of Technology, Gulbahce Campus, 35430 Urla, İzmir, Turkey

e-mail: canantari@iyte.edu.tr
}

A. O. Buyukkileci - M. F. Lahore

School of Engineering and Science, Chemical Sciences, Jacobs University Bremen, Campus Ring 1, 28759 Bremen, Germany industry. The world production of citrus production was reported to be 88 million tons per year [1], whereas only part of it was utilized as cattle feed, organic fertilizer or in the extraction of pectin [2]. The presence of high amount of soluble and insoluble carbohydrates in the citrus peel makes it an attractive substrate for bioprocesses. It can be utilized directly for the production of hydrolytic enzymes [3-8]. The insoluble polysaccharides of OP such as cellulose, hemicelluloses and pectin can be degraded to sugars by pretreatments and enzymatic hydrolysis, and used for the production of value-added products such as ethanol and various enzymes [9-12].

Pectin, a complex polysaccharide found mainly in the primary cell wall of plants, is hydrolyzed by a group of enzymes called pectinases. Pectinases have long been used in fruit juice industry to increase juice yield and clarity by degrading the pectic substances present in the fruit [13]. There are several other applications of pectinases in food, textile, and paper industries and in waste water treatment $[14,15]$. Pectinases (pectinolytic enzymes) are classified mainly in three groups: protopectinases, de-esterifying pectinases (pectin esterases) and depolymerizing pectinases (hydrolases and lyases). Pectin and pectate lyases (transeliminases) cleave pectin and pectic acid, respectively, through $\beta$-elimination, generating an unsaturated $\mathrm{C}$ bond. Polymethyl galacturonase and polygalacturonases, which act on pectin and pectic acid, respectively, are the hydrolytic pectinases. Depolymerizing pectinases act either randomly (endo-) or on the terminal residue (exo-). Pectinases are widely distributed among fungi, bacteria and plants; however, commercial production depends mainly on fungal sources [16]. Pectinolytic enzymes can be produced by several species such as, Aspergillus, Penicillium, Fusarium, Rhizopus, Trichoderma, Bacillus and Erwinia [17, 18]. Aspergillus niger has been the most studied fungus and is 
the most commonly used fungal species for industrial production of pectinases [16]. It has previously been shown that A. sojae can produce exo-polygalacturonase in submerged $[8,19,20]$ and solid-state cultures $[7,21]$.

In submerged culture, fungi exhibit different morphological forms ranging from dispersed mycelial growth to pellets of various sizes. Desired morphology depends on the fungus and the product, e.g., penicillin production by $P$. chrysogenum requires free mycelia, while pellets are required for citric acid production by $A$. niger [22, 23]. The main factors affecting the morphology are: type of strain, $\mathrm{pH}$, temperature, medium composition, aeration, and inoculum size besides the genetic factors. Generally, filamentous growth yields higher biomass with highly viscous broths of non-Newtonian behavior [24]. Due to the high viscosity, higher agitation rates, more power is required to attain desired mixing and oxygen transfer [25]. Pellet morphology has the advantage of exhibiting non-viscous broth with Newtonian behavior, so that better mixing and aeration can be provided and also separation of biomass from the broth is simpler [19]. However, the interior of the pellets based on it compactness degree can be sometimes nutrient and oxygen limited, where growth and product synthesis are impaired [24, 26].

A. sojae was previously shown in submerged cultures to utilize efficiently some agro-industrial products as substrates for exo-PG production [8]. In this study, utilization of OP, a food industrial waste product, was investigated in an attempt to propose an economical exo-PG production process with high yield and desired pellet morphology, which could ease the subsequent downstream processing and decrease the operational cost, encountered in most industrial fungal fermentations. Moreover, developing a very simple and costeffective media formulation by utilizing the waste and returning in into a value-added product such as the exo-PG would not only reduce the raw material cost but also would serve as an example where similar fungal fermentation is used in the production of other products. Such a medium formulation due to its low $\mathrm{pH}$ formation trend would also serve as a solution to microbial contamination problems faced by many industrial fungal fermentations causing high economical losses. Therefore, taking these points into consideration, medium components were optimized and cultural conditions yielding fungal pellets were specified.

\section{Materials and methods}

\section{Materials}

OP (Aurantii amari epicarpium et mesocarpium) (Bombastus-Werke AG, Freital, Germany) was purchased from the local market in Bremen, Germany. All other chemicals were analytical grade and obtained from Applichem (Darmstadt, Germany), Sigma (St. Louis, MO, USA), or Fluka (Steinheim, Germany).

\section{Microorganism}

A. sojae mutant derived from A. sojae ATCC 20235 by random UV mutation was used in this study. The organism was maintained and sporulated on solid medium at $30{ }^{\circ} \mathrm{C}$ for 5 days. This medium was composed of $(\mathrm{g} / \mathrm{L})$ glycerol (45), sugar beet syrup (45), peptone (18), $\mathrm{NaCl}$ (5), $\mathrm{FeSO}_{4} \cdot 7 \mathrm{H}_{2} \mathrm{O}(0.015), \quad \mathrm{KH}_{2} \mathrm{PO}_{4}(0.060), \quad \mathrm{MgSO}_{4} \cdot 7 \mathrm{H}_{2} \mathrm{O}$ (0.050), $\mathrm{CuSO}_{4} \cdot 5 \mathrm{H}_{2} \mathrm{O}(0.012), \mathrm{MnSO}_{4} \cdot \mathrm{H}_{2} \mathrm{O}(0.015)$, and agar (20). Spores were collected and suspended in $0.01 \mathrm{~g} / \mathrm{L}$ Tween 80. Spore concentration in the suspension was determined by counting the spores on a hemocytometer. A volume of spore suspension required to obtain the desired initial spore concentration was added to broth to initiate fermentation.

\section{Shake flask cultures}

Flask cultures were carried out in $250 \mathrm{~mL}$ flasks with $50 \mathrm{~mL}$ working volume. After sterilization at $121{ }^{\circ} \mathrm{C}$ for $15 \mathrm{~min}$, flasks were inoculated with $4.0 \times 10^{5}$ spores $/ \mathrm{mL}$, unless otherwise stated. Incubation was done at $30^{\circ} \mathrm{C}$ and $250 \mathrm{rpm}$ in shaking incubators (New Brunswick Scientific, NJ, USA).

Preliminary exo-PG production tests were carried out in the presence of OP, maltrin $(60 \mathrm{~g} / \mathrm{L})$ and AS $(8 \mathrm{~g} / \mathrm{L})$. Medium optimization studies were conducted accordingly, and selected medium was used in the subsequent fermentations. Effect of spore concentration was investigated both in the optimum medium and also in M2 medium, which was composed of OP $(34 \mathrm{~g} / \mathrm{L})$, maltrin $(140 \mathrm{~g} / \mathrm{L})$, AS $(8 \mathrm{~g} /$ L), $\mathrm{NaH}_{2} \mathrm{PO}_{4} \cdot \mathrm{H}_{2} \mathrm{O}(3.3 \mathrm{~g} / \mathrm{L})$ and $\mathrm{Na}_{2} \mathrm{HPO}_{4} \cdot 2 \mathrm{H}_{2} \mathrm{O}(3.2 \mathrm{~g} / \mathrm{L})$. $\mathrm{M} 2$ was used as seed culture medium in bioreactor studies.

\section{Bioreactor cultures}

The optimum medium was tested in $5 \mathrm{~L}$ (Biostat B plus, Sartorius, Gottingen, Germany) and 30 L (Techfors; Infors AG, Bottmingen-Basel, Switzerland) bioreactors with 4 and $18 \mathrm{~L}$ working volume, respectively. Five-litre bioreactor was sterilized at $121{ }^{\circ} \mathrm{C}$ for $45 \mathrm{~min}$ in the autoclave, while $30 \mathrm{~L}$ was sterilized in situ at $121{ }^{\circ} \mathrm{C}$ for $15 \mathrm{~min}$. The bioreactors were inoculated either directly with spores or with a seed culture (see section "Results and discussion""Use of pellets as inoculum" for seed culture conditions). In both bioreactors temperature, stirring speed and aeration were kept at $30{ }^{\circ} \mathrm{C}, 500 \mathrm{rpm}$ and $0.5 \mathrm{vvm}$, respectively. In these cultures, $\mathrm{pH}$ was not maintained except the constant $\mathrm{pH}$ study in 5-L bioreactor, in which $\mathrm{pH}$ was kept constant at 4.0 by automatic addition of $\mathrm{NaOH}(4 \mathrm{~N})$. Batch cultures 
Table 1 FCCC experimental design and the results of the first (a) and second (b) optimization study (coded levels are given in parentheses)

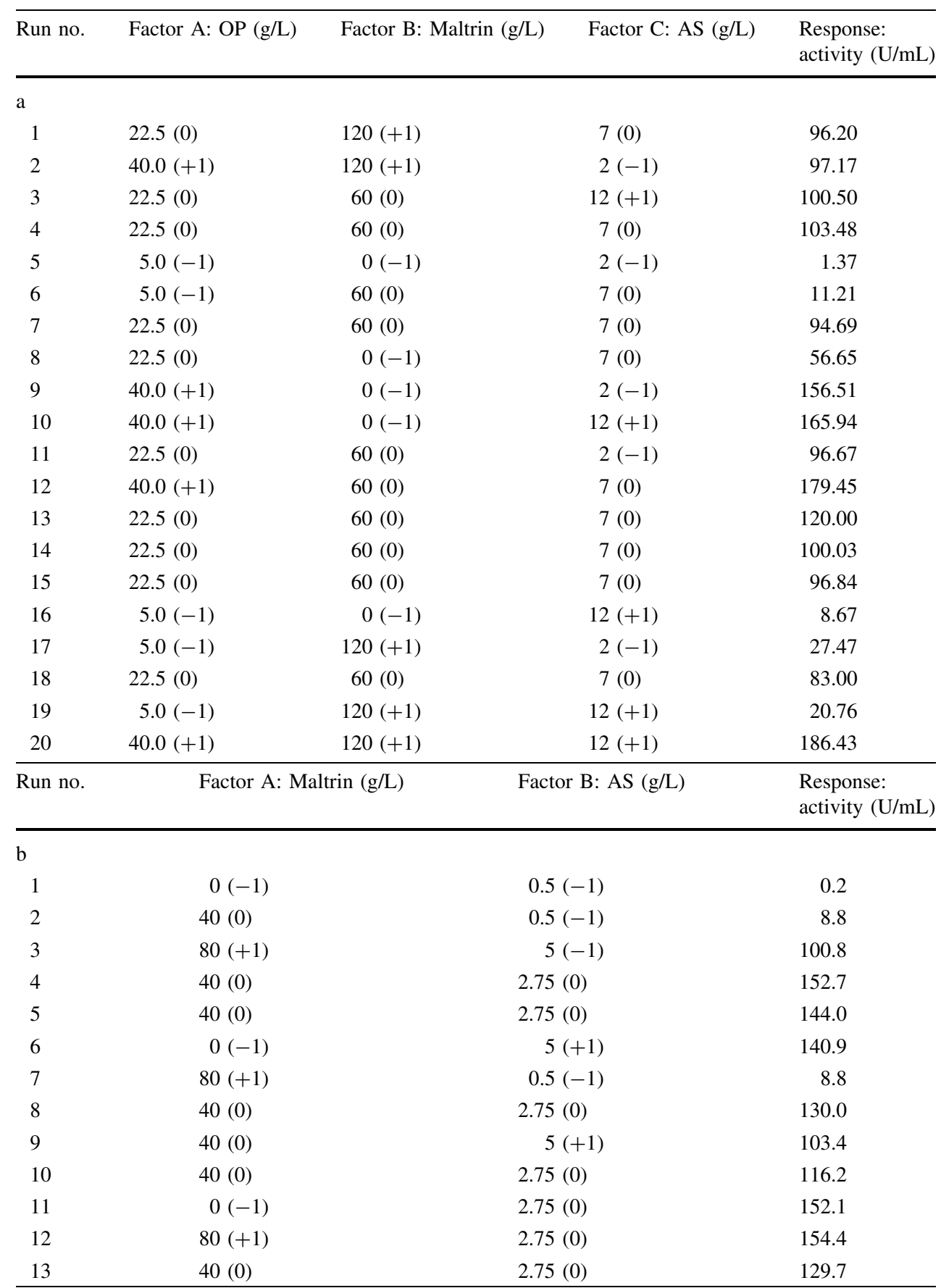

in the bioreactors were conducted in duplicates and results of single representative runs were reported.

Two fed-batch cultures with different feeding rates were conducted in the 5-L bioreactor under the conditions similar to that of batch cultures. Fermentations were started as batch with a working volume of $2.5 \mathrm{~L}$ inoculated with $5 \%$ seed culture. Fermentation was run batch wise for $24 \mathrm{~h}$, afterwards feeding started and continued until the culture volume reached 4.1-4.4 L. Sterile feed medium formulated according to the results of the medium optimization study was added to the bioreactor via a peristaltic pump.
Analytical methods

At intervals, samples were collected from the shake flasks and bioreactors, centrifuged and kept at $4{ }^{\circ} \mathrm{C}$ for enzymatic analysis or at $-18{ }^{\circ} \mathrm{C}$ for sugar analysis. Total sugar concentration was measured by Phenol-Sulfuric acid method according to DuBois et al. [27]. Sucrose solutions with known concentrations were used as standards.

Exo-PG assay was based on measuring the amount of reducing sugar released upon incubation of the enzyme sample with its polymeric substrate. Culture filtrate 

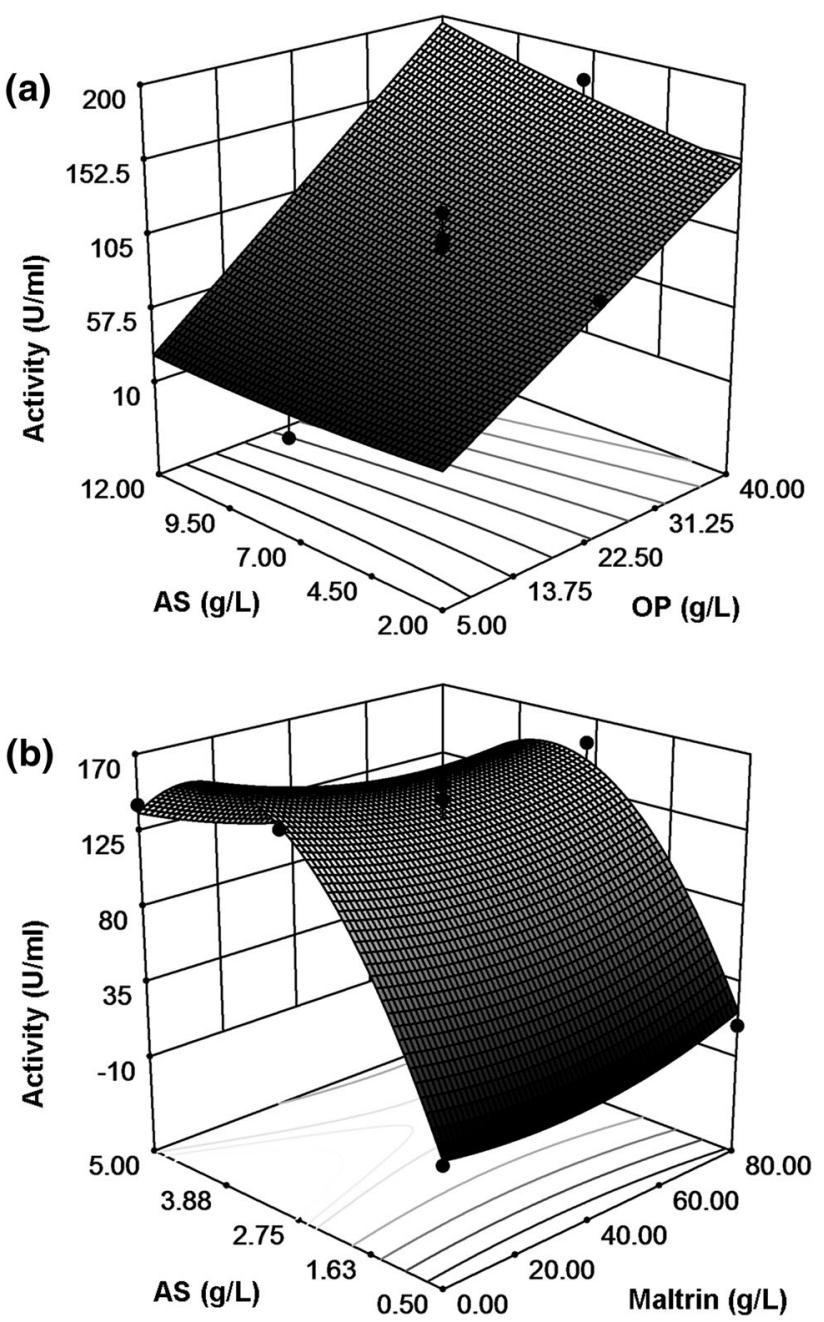

Fig. $13 \mathrm{D}$ model graph showing the interaction effects of a AS and $\mathrm{OP}$ in the presence of $60 \mathrm{~g} / \mathrm{L}$ maltrin $\mathbf{b}$ of AS and maltrin on exo-PG activity in the first and second optimization studies, respectively

$(86 \mu \mathrm{L})$ containing exo-PG was mixed with $100 \mathrm{mM}$ acetate buffer $(\mathrm{pH} 4.8$ ) containing $2.4 \mathrm{~g} / \mathrm{L}$ of polygalacturonic acid $(400 \mu \mathrm{L})$ [28]. After incubating at $40{ }^{\circ} \mathrm{C}$ in a water bath for $20 \mathrm{~min}$, enzymatic reaction was stopped by immersing the reaction tubes in boiling water for $10 \mathrm{~min}$. Reducing sugar released was quantified by NelsonSomogyi method using galacturonic acid as the standard $[29,30]$. One unit of exo-PG activity was defined as the enzyme that catalyzes the release of $1 \mu \mathrm{mol}$ of product per unit volume of culture filtrate per unit time under assay conditions.

\section{Experimental design}

Medium composition was optimized using response surface methodology, face centered central composite (FCCC) design. Concentrations of the medium components were used as the factors, while exo-PG activity was taken as the response. A second-order polynomial of the following form was fitted,

$Y=\beta_{\mathrm{o}}+\sum_{i=1}^{k} \beta_{i} X_{i}+\sum_{i=1}^{k} \beta_{i i} X_{i}^{2}+\sum_{i} \sum_{j} \beta_{j} X_{i} X_{j}+\varepsilon$

where $Y$ is the predicted response, $k$ is the number of factor variables, $\beta_{0}$ is the model constant, $\beta_{\mathrm{i}}$ is the linear coefficient, $X_{i}$ is the factor variable in its coded form, $\beta_{i i}$ is the quadratic coefficient, $\beta_{i j}$ is the interaction coefficient, and $\varepsilon$ is the error factor. The variables were coded according to Eq. 2:

$x=\frac{\text { actual }-(\text { low level }+ \text { high level }) / 2}{(\text { high level }- \text { low level }) / 2}$

The critical significance level was selected as $5 \%$ $(\alpha=0.05)$. The statistics software Design Expert (version 7.1.5 Trial, by STAT-EASE Inc., Minneapolis, USA) was used to design experiments and analyze the data.

\section{Results and discussion}

Optimization of culture medium

Initially, two OP concentrations ( 25 and $50 \mathrm{~g} / \mathrm{L}$ ) were tested in the presence of maltrin and AS. Maltrin, which was composed of maltodextrins and corn syrup solids, was used successfully as a carbon source for A. sojae in previous studies [20, 31, 32]. Exo-PG activities obtained with 25 and $50 \mathrm{~g} / \mathrm{L}$ of OP were 85.0 and $109.7 \mathrm{U} / \mathrm{mL}$, respectively. Although activity was higher, the fermentation broth was too viscous using $50 \mathrm{~g} / \mathrm{L}$ of OP. Therefore, in the following optimization study, the upper limit of OP concentration was set to $40 \mathrm{~g} / \mathrm{L}$. FCCC design with the coded and actual levels of the factors and the activities after $120 \mathrm{~h}$ are shown in Table 1a. According to the ANOVA results, the significant $(p<0.05)$ terms besides the model were the $\mathrm{OP}$ and AS concentrations and their interactions and the quadratic term of maltrin concentration. The resulting model equation in terms of coded factors was as follows:

$$
\begin{aligned}
\text { Activity }= & 106.88+79.09 A+2.38 B+11.75 C \\
& -8.76 A B+12.39 A C+7.63 B C \\
& -0.045 A^{2}-9.17 B^{2}+1.61 C^{2}
\end{aligned}
$$

According to the model, exo-PG activity increased linearly with OP concentration in the range of this design (5-40 g/L) (Fig. 1a). Although a similar trend was observed for the concentrations of AS, a careful inspection of the results showed that even the lowest amount of AS yielded considerable activity values. Interestingly, OP supplemented with sugar beet syrup was previously shown to have an adverse effect on exo-PG production by the 
Table 2 Design and results of validation experiments in shake flask cultures $(250 \mathrm{~mL}$ flasks with $50 \mathrm{~mL}$ working volume)

\begin{tabular}{llclll}
\hline $\begin{array}{l}\text { Run } \\
\text { number }\end{array}$ & $\begin{array}{l}\text { OP } \\
(\mathrm{g} / \mathrm{L})\end{array}$ & $\begin{array}{l}\text { Maltrin } \\
(\mathrm{g} / \mathrm{L})\end{array}$ & $\begin{array}{l}\text { AS } \\
(\mathrm{g} / \mathrm{L})\end{array}$ & $\begin{array}{l}\text { Predicted } \\
\text { activity } \\
(\mathrm{U} / \mathrm{mL})\end{array}$ & $\begin{array}{l}\text { Measured } \\
\text { activity } \\
(\mathrm{U} / \mathrm{mL})\end{array}$ \\
\hline 1 & 40 & 4.0 & 4.55 & 149.4 & 143.3 \\
2 & 40 & 26.3 & 3.51 & 149.6 & 138.6 \\
3 & 40 & 0.0 & 2.75 & 153.9 & 141.2 \\
4 & 40 & 80.0 & 2.75 & 144.2 & 140.1 \\
\hline
\end{tabular}

Activities are average of two runs

same strain when used at concentrations above $10 \mathrm{~g} / \mathrm{L}$ [8]. Similarly, based on a study conducted by Nighojkar et al. [33], PG production by alginate immobilized A. niger in submerged culture decreased when OP concentration was above $15 \mathrm{~g} / \mathrm{L}$. Teixeira et al. [34] also observed decreased exo-PG production by $A$. japonicus when the pectin concentration in the liquid medium was increased from 5 to $10 \mathrm{~g} / \mathrm{L}$. On the other hand, Galiotou-Panayotou et al. [35] reported a consistent increase in PG activity with the increase of pectin concentrations up to $30 \mathrm{~g} / \mathrm{L}$.

According to the results of the first optimization study, another RSM design (FCCC) was conducted, in which OP concentration was kept constant at $40 \mathrm{~g} / \mathrm{L}$ and the ranges of maltrin and AS concentrations were narrowed down to $0-80$ and $0.5-5.0 \mathrm{~g} / \mathrm{L}$, respectively (Table $1 \mathrm{~b}$ ). Based on the results of this study, the model was significant and the lack of fit was insignificant at the $95 \%$ confidence level. There was a good agreement between the predicted (0.887) and the adjusted $R^{2}(0.951)$ terms. The linear AS and the quadratic $\mathrm{AS}^{2}$ terms were the factors affecting the activity significantly $(p<0.05)$. The model equation of the second design was as follows:

$$
\begin{aligned}
\text { Activity }= & 136.21-4.85 A+54.53 B-12.17 A B \\
& +12.87 A^{2}-84.29 B^{2}
\end{aligned}
$$

Model plots showed that maximum activity lied in the AS concentration range of $2.75-5 \mathrm{~g} / \mathrm{mL}$ (Fig. 1b). Maltrin did not have a significant influence on the activity in the ranges $(0-80 \mathrm{~g} / \mathrm{L})$ studied (Fig. 1b). Validity of the model was tested by conducting experiments at four different conditions selected to obtain high activity based on the model graph (Table 2; Fig. 1b) and according to the recommendations of the software. The measured values were in good agreement with the predicted ones (Table 2). In the presence of $40 \mathrm{~g} / \mathrm{L}$ OP and $2.75 \mathrm{~g} / \mathrm{L}$ AS, $141.2 \mathrm{U} / \mathrm{mL}$ exoPG could be produced without addition of maltrin. This showed that, a simple medium, OP supplemented with AS, was sufficient to yield significant amount of PG. No additional carbon source was needed to support the growth of the microorganism and PG production, which showed that the soluble sugar content of the OP was sufficient. Around $23-25 \%$ of the dry weight of OP is the soluble (non-structural) carbohydrates composed mainly of glucose, fructose and sucrose [10,11,36-38]. OP also contains insoluble cellulose, hemicellulose as well as pectin at appreciable amounts [10, 38]. These may have been hydrolyzed during the cultivation by the probable hydrolytic enzymes of $A$. sojae such as cellulases or hemicellulases, to yield additional simple sugars. Apart from that, the complex nature of the OP eliminated the addition of mineral salts or high amount of nitrogen sources to the culture medium [2]. El-Sheekh et al. [5] also used OP powder efficiently as the sole carbon source for pectinase production by A. carneus, while no activity was detected when the OP was replaced by mono- and disaccharides. Same authors also demonstrated that pectinase activity was stimulated, whereas cellulase and hemicellulase activities were inhibited by AS [5]. In another study, the same amount of $(15 \mathrm{~g} / \mathrm{L})$ OP and pectin yielded similar PG activity values; however, activity was less when they were supplemented by glucose, peptone and yeast extract [33].

\section{Effect of spore concentration}

In the above-mentioned shake flask cultures $A$. sojae grew in free dispersed mycelial form, which resulted in a culture broth with high apparent viscosity [24]. This phenomenon was discussed in the previous reports of our group and $A$. sojae was shown to form pellets in submerged culture under the optimized conditions $[19,20,32]$; whereas in another study, the same organism formed small mycelial clumps (small groups of entangled mycelia) in the presence of OP and sugar beet syrup as substrates [8]. It is well known that inoculum size is one of the main factors influencing the growth form and product formation in fungal cultures $[22,39,40]$. Therefore, the effect of inoculated spore concentration on the morphology and exo-PG activity was investigated in OP-AS and in M2 medium, in an effort to obtain a pellet forming, less viscous and high exo-PG producing condition. The latter medium was optimized previously for exo-PG production by the same strain [31]. These two media were inoculated with $4.0 \times 10^{5}, 4.0 \times 10^{4}$ or $2.8 \times 10^{3}$ spores $/ \mathrm{mL}$ of culture volume. Inoculum size influenced two cultures differently (Table 3; Fig. 2). In OP-AS medium, free mycelia or mycelial clumps were the dominant morphology at high inoculum sizes. On the other hand, fluffy pellet formation was observed at low inoculum size; however, there were free mycelia in the broth as well as the pellets. In M2 medium, pellets were formed almost at all inoculums levels; however, at the low level, small compact pellets were dominant with only small amount of free mycelia around the pellets (Fig. 2). Exo-PG activity in the OP-AS medium 
Table 3 Effect of spore concentration on PG activity and morphology in shake flask cultures $(250 \mathrm{~mL}$ flasks with $50 \mathrm{~mL}$ working volume)

\begin{tabular}{|c|c|c|c|c|}
\hline Medium & $\begin{array}{l}\text { Spore } \\
\text { concentration } \\
\text { (spores } / \mathrm{mL} \text { ) }\end{array}$ & $\begin{array}{l}\text { Activity } \\
\text { after } 72 \mathrm{~h} \\
(\mathrm{U} / \mathrm{mL})\end{array}$ & $\begin{array}{l}\text { Activity } \\
\text { after } 120 \mathrm{~h} \\
(\mathrm{U} / \mathrm{mL})\end{array}$ & Morphology \\
\hline OP-AS & $4.0 \times 10^{5}$ & 83.1 & 141.2 & $\begin{array}{l}\text { Free } \\
\text { mycelia }\end{array}$ \\
\hline OP-AS & $4.0 \times 10^{4}$ & 79.7 & 137.1 & $\begin{array}{r}\text { Mycelial } \\
\text { clumps }\end{array}$ \\
\hline OP-AS & $2.8 \times 10^{3}$ & 72.2 & 138.7 & $\begin{array}{l}\text { Pellets-Free } \\
\text { mycelia }\end{array}$ \\
\hline M2 & $4.0 \times 10^{5}$ & 11.8 & 50.2 & $\begin{array}{l}\text { Large } \\
\text { pellets- } \\
\text { clumps }\end{array}$ \\
\hline M2 & $4.0 \times 10^{4}$ & 20.3 & 80.8 & Clumps \\
\hline M2 & $2.8 \times 10^{3}$ & 65.1 & 155.7 & Pellets \\
\hline
\end{tabular}

Activities are average of two runs

was not influenced by the inoculum size; 141.2 and 138.7 U/mL PG activities were observed after $120 \mathrm{~h}$ at high and low inoculum sizes, respectively (Table 3 ). In the M2 medium, the effect was drastic; the exo-PG activity increased significantly as the spore concentration decreased (Table 3). At low inoculum level, $155.7 \mathrm{U} / \mathrm{mL}$ PG activity could be obtained, which was ca. $12 \%$ higher compared to levels obtained in OP-AS medium. Comparison of the enzyme activity and the morphology in the shake flask cultures showed that formation of pellets in OP-AS medium did not improve the exo-PG activity, whereas in M2 medium more enzyme activity was observed when the pellets were smaller. Considering the high exo-PG production levels and pellet growth, the spore concentration of $2.8 \times 10^{3}$ spores $/ \mathrm{mL}$ was concluded to be the best inoculum size for both media in the ranges investigated. The enzyme activity trend observed in M2, but not in OP-AS medium, was in accordance with the results of Friedrich et al. [41], who observed decreased PG activity with increasing inoculum size in A. niger cultures, while pectin lyase showed the opposite relation. Same authors added potassium hexacyanoferrate II hydrate to culture medium and morphology changed from loose pellets to smaller compact ones associated with a marked increase in PG enzyme activity [41].

The effect of spore concentration was also tested in the 5 -L bioreactor with a working volume of $4 \mathrm{~L}$. The OP-AS medium was inoculated with either $4.0 \times 10^{5}$ or $2.8 \times 10^{3}$ spores $/ \mathrm{mL}$, where exo-PG activity (Fig. 3a) and $\mathrm{pH}$ and dissolved $\mathrm{O}_{2}$ (Fig. 3b) profiles were compared. At high inoculum size, activity was $80 \mathrm{U} / \mathrm{mL}$ after $120 \mathrm{~h}$ and increased slightly to $94 \mathrm{U} / \mathrm{mL}$ in the next $48 \mathrm{~h}$. These values were approximately $40 \%$ lower than the ones obtained in the shake flask cultures using the same medium and the same inoculum concentration. The initial $\mathrm{pH}$ of the
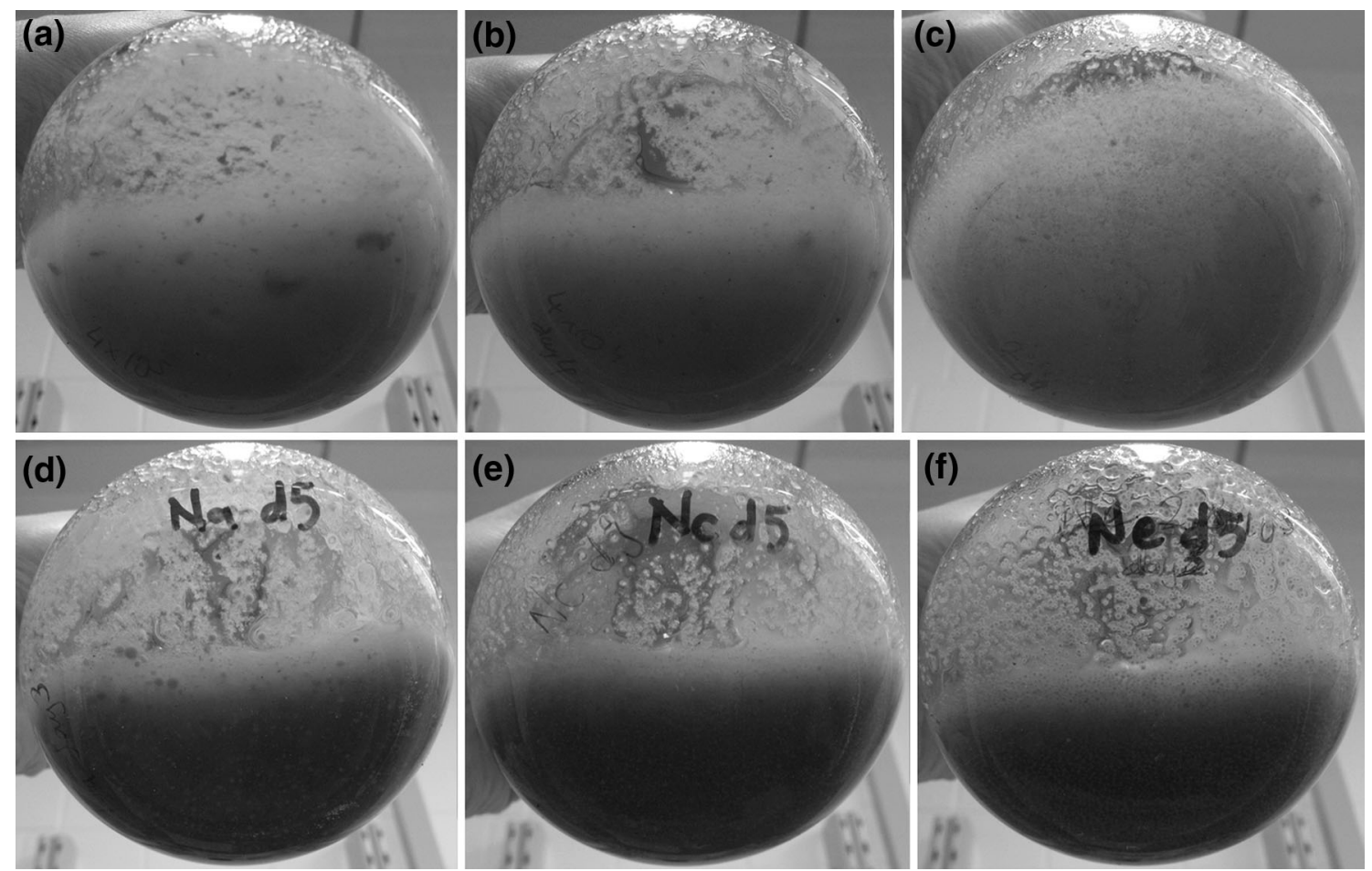

Fig. 2 Flask photographs showing the effect of spore concentration on morphology after $96 \mathrm{~h}$. a, b, and $\mathbf{c}$ OP-AS medium; d, e, and f M2 medium; a, d $4 \times 10^{5}$ spores $/ \mathrm{mL} ; \mathbf{b}, \mathbf{e} 4 \times 10^{4}$ spores $/ \mathrm{mL} ; \mathbf{c}, \mathbf{f} 2.8 \times 10^{3}$ spores $/ \mathrm{mL}$ 

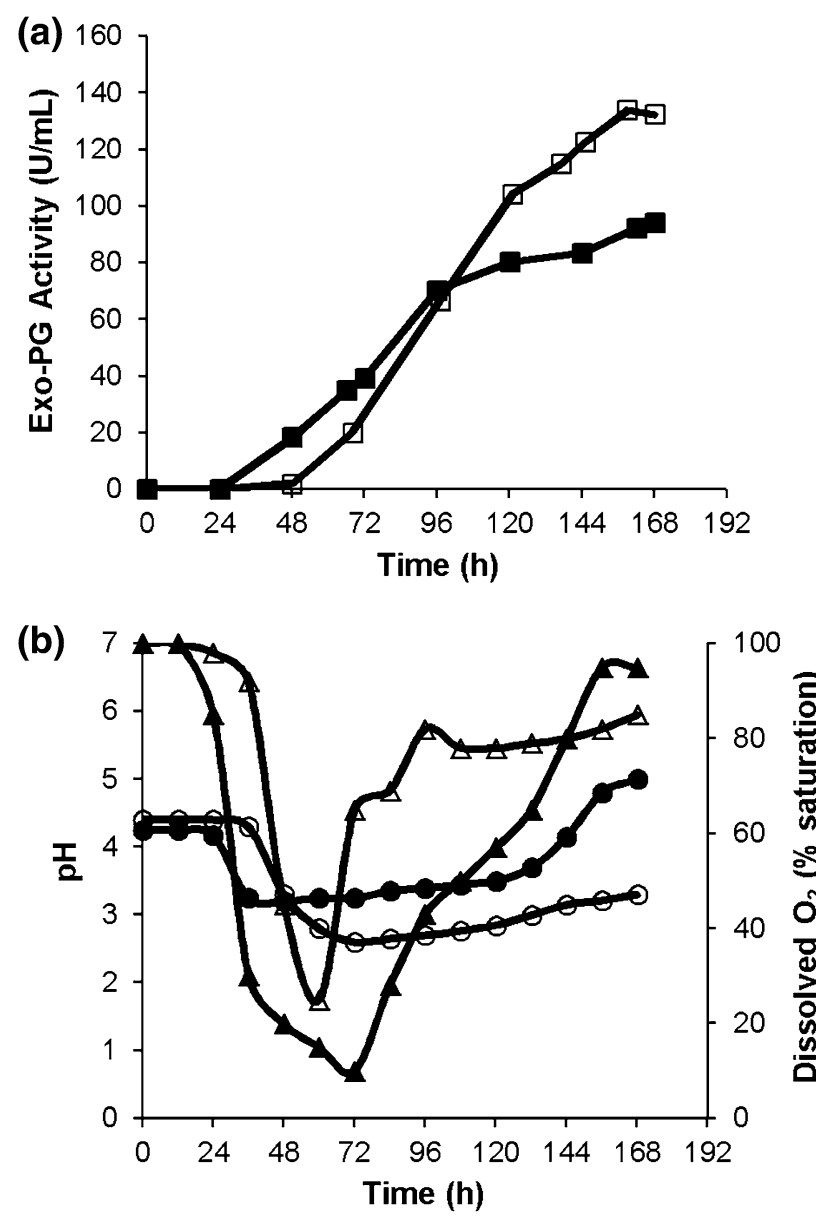

Fig. 3 Effect of inoculum size on PG production in OP-AS medium in the 5-L bioreactor. a Exo-PG activity, b pH (circles) and dissolved $\mathrm{O}_{2}$ (triangles). Closed marks $4 \times 10^{5}$ spores $/ \mathrm{mL}$, open marks $2.8 \times 10^{3}$ spores $/ \mathrm{mL}$

medium was around 4.3 and decreased sharply between 24 and $36 \mathrm{~h}$ to 3.2. Starting from $48 \mathrm{~h}, \mathrm{pH}$ increased slowly to 5 in the next $120 \mathrm{~h}$. Similarly, dissolved $\mathrm{O}_{2}$ showed a sharp decrease between 24 and $72 \mathrm{~h}$ and increased afterwards. At low inoculum size, on the other hand, enzyme production started later, but the activity increased to $134.1 \mathrm{U} / \mathrm{mL}$ in $160 \mathrm{~h}$. $\mathrm{pH}$ trend was similar to the high inoculum size case, but the values were slightly lower. Dissolved $\mathrm{O}_{2}$ trend was also similar; however, the increase following the sharp decrease was rapid, so that level was generally higher than the former case. Decreasing the inoculum size resulted in approximately $45 \%$ increase in the exo-PG activity in the bioreactor, whose effect was more pronounced after $96 \mathrm{~h}$ (Fig. 3a). The lag phase of enzyme production with low inoculum size was longer than the one with larger inoculum size shown in Fig. 3a; however, the maximum exo-PG productions of two fermentation process both reached their maximum level simultaneously. In the early phase of the low inoculum size culture, biomass concentration was

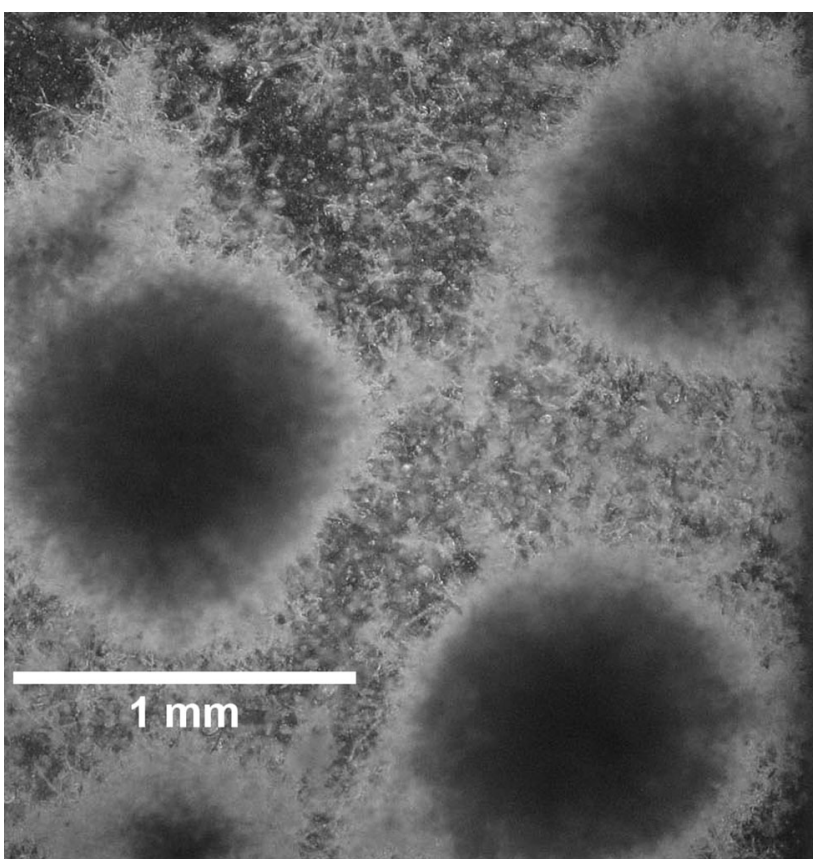

Fig. 4 Appearance of fungal pellets and free mycelia under microscope after $96 \mathrm{~h}$ in the 5-L bioreactor inoculated with $2.8 \times 10^{3}$ spores $/ \mathrm{mL}$

probably low as a result of the low number of inoculated spores, thus no exo-PG was detected in the first $48 \mathrm{~h}$ (Fig. 3a). On the other hand, enzyme production rate was high in this culture compared to one in high inoculum case (Fig. 3a). Although enzyme production started earlier in the latter case, the low dissolved $\mathrm{O}_{2}$ levels (Fig. 3b) may have inhibited the enzyme production, thus resulted in a lower production rate. As a result of these, the maximum exo-PG productions were obtained in similar time points. Exo-PG production rates between 48 and $120 \mathrm{~h}$ were calculated as 1.31 and $0.91 \mathrm{U} / \mathrm{mL} \mathrm{h}$ for the low and high inoculum sizes, respectively. In the same medium, the tested inoculum sizes had an influence on the activity levels in the fermenter, unlike in the shake flasks. This could be attributed to different aeration and mixing regimes in two systems pronouncing the effect of inoculum sizes (Table 3; Fig. 3a).

At high inoculum size, free and clumped mycelia were observed, while at low inoculum size pellets were the dominant growth form. Pellets had compact cores and hairy regions in the outer parts and there were free mycelia surrounding the pellets (Fig. 4). Growth form in the former case created mixing problems in the bioreactor, which was apparent by the poorly mixed zones in the broth in high inoculum size culture. Inefficient mixing and probably higher amount of biomass in the high inoculum case resulted in poor aeration of the broth, as can be deduced by the lower dissolved $\mathrm{O}_{2}$ profile [22]. Consequently, enzyme 
production was impaired in this culture. In the latter case, the problem was not so severe, although there were poorly mixed regions in the culture broth as well, probably due to the free mycelia associated with the pellets (Fig. 4). However, it should not be overlooked that enhancement of PG production in pellet form can be partly a result of altered cellular metabolism and enzyme secretion due to limitations in oxygen and nutrient supply and in removal of metabolic products [42].

Tari et al. [20] optimized the culture conditions for $A$. sojae ATCC20235 and observed increased PG activity with increasing inoculum size. Maximum PG activity (13.5 U/ $\mathrm{mL}$ ) was achieved at an inoculum size of $4 \times 10^{5}$ spores/ $\mathrm{mL}$, where the growth was as small pellets. This contradictory result can be explained by the presence of a less viscous broth containing simple carbon sources (maltrin and glucose) in that study. In this study, however, the OP generated a viscous broth, so that pelleted growth, thus sufficient mixing and aeration could only be obtained at a lower inoculum size $\left(2.8 \times 10^{3}\right.$ spores $\left./ \mathrm{mL}\right)$. In another study, where agro-based products were utilized for exo-PG production by $A$. sojae M5/6, the inoculum size of $4 \times 10^{5}$ spores $/ \mathrm{mL}$ resulted in mycelial clumps and viscous culture broths in the presence of all substrates [8]. Hermersdörfer et al. [42] observed increased PG synthesis by A. niger in a synthetic medium when it grew as a compact mycelia, which was defined as a large ball with a diameter of $40 \mathrm{~mm}$. The PG activity was considerably lower when the growth was in the form of either diffuse mycelia or pellets of 2-10 $\mathrm{mm}$ in diameter [42]. A similar trend was observed for $R$. oryzae where low inoculum size induced compact large mycelial mass and high lactate production, whereas the fungus formed dispersed mycelia and produced low lactate but high ethanol at high inoculum sizes [39]. Couri et al. [43], on the other hand, explained the higher PG synthesis by the loose pellet morphology of A. niger induced by the addition of some metal ions. Therefore, the relation between the morphology and product synthesis in fungal cultures is complex and depends on the strain and culture conditions, among other factors.

Use of pellets as inoculum

In the above study $\mathrm{pH}, \mathrm{dO}_{2}$ and exo-PG activity profiles showed that in the first $36-48 \mathrm{~h}$ of the low inoculum size run there was only a little microbial activity in the culture (Fig. 3a, b). In this part of the study, a seed culture was used to inoculate the bioreactor in an effort to decrease the length of the lag phase. When the effect of spore concentration was investigated, small pellets were obtained in M2 medium (Table 3; Fig. 2). These pellets had the potential to be used as an inoculum for exo-PG production in OP-AS medium. In fact, high levels of exo-PG could be obtained
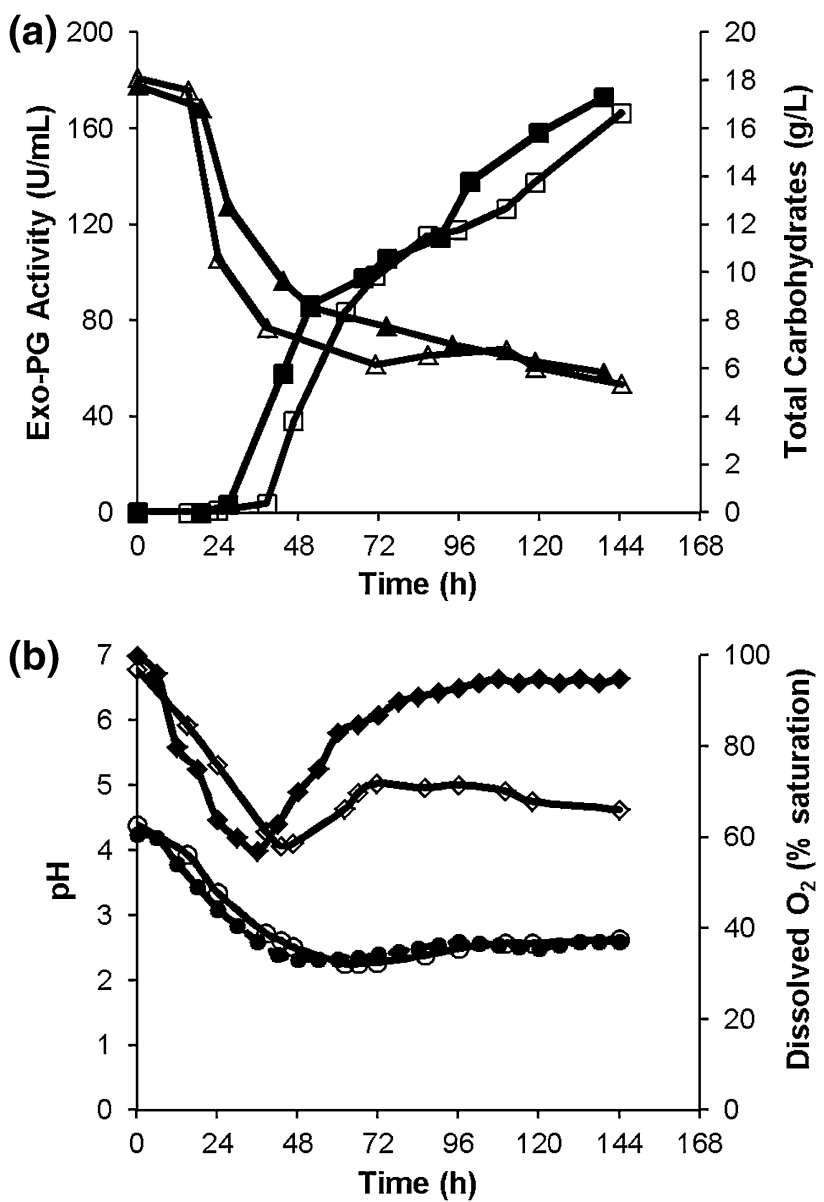

Fig. 5 a Activity (squares) and carbohydrate utilization (triangles), and $\mathbf{b ~ p H}$ (circles) and $\mathrm{dO}_{2}$ (rhombs) profiles of $4 \mathrm{~L}$ (closed marks) and $18 \mathrm{~L}$ (empty marks) batch cultures inoculated with seed culture

in M2 medium itself; however, OP-AS medium was a simpler and more economical medium.

A. sojae mutant was grown in the form of pellets in $\mathrm{M} 2$ medium inoculated initially with $2.8 \times 10^{3}$ spores $/ \mathrm{mL}$ in shake flask for $48 \mathrm{~h}$ and $200 \mathrm{~mL}$ of this culture was added as a seed culture to the 5-L bioreactor containing $3.8 \mathrm{~L} \mathrm{OP-}$ AS medium. Similarly, 30-L bioreactor with a working volume of $18 \mathrm{~L}$ was inoculated with $900 \mathrm{~mL}$ of the same seed culture. Throughout the cultivations in the bioreactors inoculated by pelleted fungus, pellets were the dominant morphology. There were a few free mycelia as well; however, there was no apparent mixing problem. Cultures at two scales followed similar activity, sugar utilization (Fig. 5a), and $\mathrm{pH}$ trends (Fig. 5b), while there was a difference in $\mathrm{dO}_{2}$ levels (Fig. 5b) in the later stages of the cultivations. Exo-PG activity started earlier compared to spore-inoculated case and showed a steep increase at a rate of $3.3 \mathrm{U} / \mathrm{mL} \mathrm{h}$ after $24-36 \mathrm{~h}$ of inoculation. After $96 \mathrm{~h}$, enzyme levels at both scales were around $120 \mathrm{U} / \mathrm{mL}$. The endpoint exo-PG activities were measured as $173.0 \mathrm{U} / \mathrm{mL}$ after $139 \mathrm{~h}$ and $166.5 \mathrm{U} / \mathrm{mL}$ after $144.5 \mathrm{~h}$ in 4 and $18 \mathrm{~L}$ 
Table 4 Feeding profiles of fed-batch cultures

\begin{tabular}{lll}
\hline Time $(\mathrm{h})$ & \multicolumn{2}{l}{ Feeding rate $(\mathrm{mL} / \mathrm{h})$} \\
\cline { 2 - 3 } & Fed-batch 1 (FB1) & Fed-batch 2 (FB2) \\
\hline $0-24$ & 0 & 0 \\
$24-48$ & 21.6 & 10.8 \\
$48-72$ & 27.0 & 13.5 \\
$72-96$ & 32.4 & 16.2 \\
$96-120$ & - & 18.9 \\
$120-128$ & - & 21.6 \\
\hline
\end{tabular}

cultures, respectively. Thus, using a seed culture, in which A. sojae formed pellets, enhanced the exo-PG level and the productivity.

The fast increase in enzyme activity was associated with the fast sugar utilization. Initial concentration of total sugars was $18 \mathrm{~g} / \mathrm{L}$ which decreased sharply in $48 \mathrm{~h}$ to $5 \mathrm{~g} /$ L sugar remaining unutilized until the end of the fermentation (Fig. 5a). Similar declining trend was observed for both $\mathrm{pH}$ and $\mathrm{dO}_{2}$ profiles after which $\mathrm{pH}$ stabilized around 2.5 until the end of the cultivation (Fig. 5b). The decrease in $\mathrm{pH}$ can be attributed to the organic acids produced by the organism as metabolic end products. $\mathrm{dO}_{2}$ level decreased to $60 \%$ of saturation in 2 days and increased afterwards. These indicated that microbial activity stopped or continued at a very low rate after $48-72 \mathrm{~h}$. These can be explained by the low $\mathrm{pH}$ (2.5), which was below the physiological values. On the other hand, exo-PG production did not stop at low $\mathrm{pH}$, but continued at a lower rate compared to that of the first phase. Overall productivity value was calculated as $1.2 \mathrm{U} / \mathrm{mL} \mathrm{h}$ and the yield based on the final exo-PG level and the initial OP amount was around 4,200 U/g OP.

When the culture $\mathrm{pH}$ was kept constant at 4 , the sugar utilization followed a similar trend to the uncontrolled $\mathrm{pH}$ run for the first $72 \mathrm{~h}$; however, it continued in the next $72 \mathrm{~h}$ and most of the sugar was utilized unlike the uncontrolled $\mathrm{pH}$ run. $\mathrm{dO}_{2}$ decreased sharply to zero in about $72 \mathrm{~h}$ and increased after $96 \mathrm{~h}$. These indicated a prolonged activity of the organism compared to uncontrolled $\mathrm{pH}$ run. However, the maximum attainable activity was $26.6 \mathrm{U} / \mathrm{mL}$ and the secondary increase phase in activity, which was apparent at low $\mathrm{pH}$ after the sugar utilization terminated, was not observed at $\mathrm{pH} 4$.

It was previously shown that exo-PG production by $A$. sojae was induced at low $\mathrm{pH}$ values obtained under uncontrolled pH run [8]. Fontana et al. [13] observed very similar kinetics for PG production by $A$. oryzae in a liquid medium containing wheat bran and citrus pectin. In the stirred tank reactor, $\mathrm{pH}$ and $\mathrm{dO}_{2}$ decreased sharply in 24-36 $\mathrm{h}$ and increased afterwards. Cell concentration did

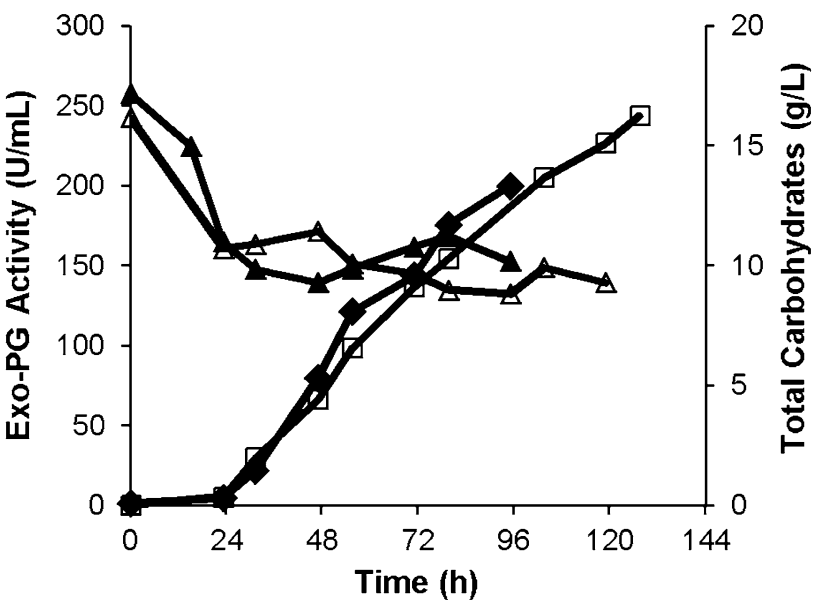

Fig. 6 Exo-PG activity (squares) and total carbohydrate (triangles) profiles of fed-batch cultures; closed marks FB1, open marks FB2

not increase after around $30-40 \mathrm{~h}$, while both exo- and endo-PG productions continued at least for $96 \mathrm{~h}$ [13]. Malvessi et al. [44] also obtained highest PG activity by $A$. oryzae at an initial $\mathrm{pH}$ of 4 , where $\mathrm{pH}$ was slightly below 3 between 24 and $72 \mathrm{~h}$.

Fed-batch culture

As indicated above, exo-PG level increased with increasing OP concentration; however, high OP concentrations generated highly viscous broths. Therefore, its level was limited to $40 \mathrm{~g} / \mathrm{L}$ throughout the study. In an effort to overcome this limitation, fed-batch cultures were conducted. The feed OP concentration was set to $80 \mathrm{~g} / \mathrm{L}$, above which concentration the medium in the feeding tank was too viscous that it could not be agitated by the magnetic stirrer and fed using the peristaltic pump. Two different feeding modes were used (Table 4); in the fast feeding run (FB1), cultivation was terminated $96 \mathrm{~h}$ after inoculation, while slow feeding (FB2) allowed a culture time of $127 \mathrm{~h}$. Feedings were stopped when the culture volumes increased to $4.1-4.4 \mathrm{~L}$ in the 5-L bioreactor.

Two runs followed similar fermentation kinetics (Fig. 6). Total carbohydrate concentration decreased to $10 \mathrm{~g} / \mathrm{L}$ in $24 \mathrm{~h}$ and remained at this value until the end of the fermentation. Thus, it was higher during the fed-batch culture compared to batch cultures (Fig. 5a). Exo-PG activity followed almost the same trend in two cultures; however, an extended production was achieved in FB2 due to prolonged fermentation time. The endpoint exo-PG activities were $200 \mathrm{U} / \mathrm{mL}$ after $96 \mathrm{~h}$ in FB1 and $244 \mathrm{U} / \mathrm{mL}$ after $127 \mathrm{~h}$ in FB2 (Fig. 6). Exo-PG productivities were calculated for the total cultivation time as 2.1 and $1.9 \mathrm{U} /$ $\mathrm{mL} \mathrm{h}$ for FB1 and FB2, respectively. These values were considerably higher than the ones obtained in batch 
fermentations. On the other hand, product yield was higher in the batch culture. In FB1 and FB2, total of 295 and $267 \mathrm{~g}$ OP was supplied including the batch phase, which correspond to yield values of 3012 and $3738 \mathrm{U} / \mathrm{g}$ OP, respectively. $\mathrm{pH}$ and $\mathrm{dO}_{2}$ trends were similar to batch cultures. pH decreased to 2.5 in $48 \mathrm{~h}$, whereas $\mathrm{dO}_{2}$ showed a minimum between 24 and $36 \mathrm{~h}$ (50\% saturation) and increased slowly to $80 \%$ saturation in time.

Results showed that exo-PG activity was 1.4-fold higher in fed-batch culture than in batch culture (Figs. 5a, 6). Slow feeding rate used in FB2 was sufficient to obtain enhanced enzyme production. The lower enzyme titer in the batch culture can be explained by depletion of a nutrient, which was overcome by addition of the nutrients in the fed-batch culture. Depletion of nutrients in the batch culture, rather than low $\mathrm{pH}$, can also be the reason for decreased production rates, since similar low $\mathrm{pH}$ values did not result in a rate decline in fed-batch culture. Although higher total carbohydrate levels were obtained in fed-batch cultures, AS or nutrients other than carbohydrates provided by the complex nature of $\mathrm{OP}$ could be the reason for enhanced exo-PG production. Enzyme yield, which is an industrially important parameter, was higher in batch cultures although end point enzyme level was low, because of the low utilized OP amount. However, considering the low cost of OP, low yield in fed-batch culture could be ignored, since the final exo-PG activity and the productivity values were considerable higher compared to batch culture.

The enzyme levels obtained in this study were higher compared to the ones reported in most of the other reports. Favela-Torres et al. [17] compared 24 studies in which exoPG was produced from pectin, glucose or plant biomass using several different microorganisms in submerged fermentations. Among the activities reported, only three of them $(162,221$ and $239 \mathrm{U} / \mathrm{mL}$, respectively) were comparable to the ones obtained in this study, while in one study $500 \mathrm{U} / \mathrm{mL}$ exo-PG was reported [34, 45-47]. Most of the other reported values were one order of magnitude lower. In previous studies of our group, $145 \mathrm{U} / \mathrm{mL}$ exo-PG was produced in a more complex medium containing sugar beet syrup and OP [8] and $93.5 \mathrm{U} / \mathrm{mL}$ exo-PG was produced from OP, supplemented with maltrin and phosphate salts [31] using the same A. sojae strain. Corresponding productivity values in fungal cultures were generally below $2 \mathrm{U} / \mathrm{mL} \mathrm{h}$, even if high activity values were obtained [8, $31,46,47]$, except that $A$. japonicus produced exo-PG at a rate of $10.41 \mathrm{U} / \mathrm{mL} \mathrm{h}$ [34] In a more recent study, $230 \mathrm{U} /$ $\mathrm{mL}$ exo-PG activity could be obtained by $A$. carbonarius in $24 \mathrm{~h}$, which also resulted in exceptionally high productivity values $(9.6 \mathrm{U} / \mathrm{mL}$ h) [48]. Rangarajan et al. [49] utilized OP extract successfully as a substrate for exo-PG production in submerged culture using A. niger and reported a yield of $6,800 \mathrm{U} / \mathrm{g}$ of $\mathrm{OP}$ used. A. giganteus produced
48.5 U/mL PG on orange bagasse [50], while activity was below $1 \mathrm{U} / \mathrm{mL}$ with immobilized $A$. niger growing on OP [33]. It should be noted that, unlike most of the other studies, in this study, a single low cost substrate (OP), which was supplemented solely with a simple inorganic $\mathrm{N}$ source (AS), was utilized.

\section{Conclusion}

A very simple and cost-effective medium was defined for exo-PG production by $A$. sojae. The medium was composed of OP, which is a food industrial by-product, and an inorganic nitrogen source, AS and no other sugar or mineral salt source were necessary. The problem of mixing and aeration was overcome by inducing pellet formation obtained by decreasing the inoculated spore concentration. Further enhancement of reactor performance and exo-PG activity was achieved using a seed culture, in which $A$. sojae was pre-grown in the form of small pellets, to inoculate the bioreactors containing OP-AS medium. Fed-batch culture prevented depletion of nutrients and allowed higher exo-PG activity and productivity than the batch culture. Low operational $\mathrm{pH}$ was also advantageous, since it eliminated the $\mathrm{pH}$ maintenance and decreased the risk of bacterial contamination. Thus, the proposed process for exo-PG production has the potential to be applied to industrial scale easily.

Acknowledgments This work was supported by TÜBITAK (Turkey) and BMBF (Germany) through the Intensified Cooperation Project of IntenC 1070602 and EUROTRANSBIO, PGSYS/ETB2008-44.

\section{References}

1. Marin FR, Soler-Rivas C, Benavente-Garcia O, Castillo J, PerezAlvarez JA (2007) By-products from different citrus processes as a source of customized functional fibres. Food Chem 100:736-741

2. Lopez JAS, Li Q, Thompson IP (2010) Biorefinery of waste orange peel. Crit Rev Biotechnol 30:63-69

3. Mamma D, Kourtoglou E, Christakopoulos P (2008) Fungal multienzyme production on industrial by-products of the citrusprocessing industry. Bioresour Technol 99:2373-2383

4. Giese EC, Dekker RFH, Barbosa AM (2008) Orange bagasse as substrate for the production of pectinase and laccase by Botryosphaeria rhodina MAMB-05 in submerged and solid state fermentation. Bioresources 3:335-345

5. El-Sheekh MM, Ismail AMS, El-Abd MA, Hegazy EM, ElDiwany AI (2009) Effective technological pectinases by Aspergillus carneus NRC1 utilizing the Egyptian orange juice industry scraps. Int Biodeterior Biodegrad 63:12-18

6. Tao NG, Shi WQ, Liu YJ, Huang SR (2011) Production of feed enzymes from citrus processing waste by solid-state fermentation with Eupenicillium javanicum. Int $\mathbf{J}$ Food Sci Technol 46:1073-1079 
7. Heerd D, Yegin S, Tari C, Fernandez-Lahore M (2012) Pectinase enzyme-complex production by Aspergillus spp. in solid-state fermentation: a comparative study. Food Bioprod Process 90:102-110

8. Buyukkileci AO, Tari C, Fernandez-Lahore M (2011) Enhanced production of exo-polygalacturonase from agro-based products by Aspergillus sojae. Bioresources 6:3452-3468

9. Oberoi HS, Vadlani PV, Nanjundaswamy A, Bansal S, Singh S, Kaur S, Babbar N (2011) Enhanced ethanol production from Kinnow mandarin (Citrus reticulata) waste via a statistically optimized simultaneous saccharification and fermentation process. Bioresour Technol 102:1593-1601

10. Pourbafrani M, Forgacs G, Horvath IS, Niklasson C, Taherzadeh MJ (2010) Production of biofuels, limonene and pectin from citrus wastes. Bioresour Technol 101:4246-4250

11. Wilkins MR, Widmer WW, Grohmann K (2007) Simultaneous saccharification and fermentation of citrus peel waste by Saccharomyces cerevisiae to produce ethanol. Process Biochem 42:1614-1619

12. Wilkins MR, Widmer WW, Grohmann K, Cameron RG (2007) Hydrolysis of grapefruit peel waste with cellulase and pectinase enzymes. Bioresour Technol 98:1596-1601

13. Fontana RC, Polidoro TA, da Silveira MM (2009) Comparison of stirred tank and airlift bioreactors in the production of polygalacturonases by Aspergillus oryzae. Bioresour Technol 100:4493-4498

14. Kashyap DR, Vohra PK, Chopra S, Tewari R (2001) Applications of pectinases in the commercial sector: a review. Bioresour Technol 77:215-227

15. Ribeiro DS, Henrique SMB, Oliveira LS, Macedo GA, Fleuri LF (2010) Enzymes in juice processing: a review. Int J Food Sci Tech 45:635-641

16. Jayani RS, Saxena S, Gupta R (2005) Microbial pectinolytic enzymes: a review. Process Biochem 40:2931-2944

17. Favela-Torres E, Volke-Sepulveda T, Viniegra-Gonzalez G (2006) Production of hydrolytic depolymerising pectinases. Food Technol Biotechnol 44:221-227

18. Zeni J, Cence K, Grando CE, Tiggermann L, Colet R, Lerin LA, Cansian RL, Toniazzo G, de Oliveira D, Valduga E (2011) Screening of pectinase-producing microorganisms with polygalacturonase activity. Appl Biochem Biotechnol 163:383-392

19. Gogus N, Tari C, Oncu S, Unluturk S, Tokatli F (2006) Relationship between morphology, rheology and polygalacturonase production by Aspergillus sojae ATCC 20235 in submerged cultures. Biochem Eng J 32:171-178

20. Tari C, Gögus N, Tokatli F (2007) Optimization of biomass, pellet size and polygalacturonase production by Aspergillus sojae ATCC 20235 using response surface methodology. Enzyme Microb Technol 40:1108-1116

21. Ustok FI, Tari C, Gogus N (2007) Solid-state production of polygalacturonase by Aspergillus sojae ATCC 20235. J Biotechnol 127:322-334

22. Pazouki M, Panda T (2000) Understanding the morphology of fungi. Bioprocess Eng 22:127-143

23. Paul GC, Priede MA, Thomas CR (1999) Relationship between morphology and citric acid production in submerged Aspergillus niger fermentations. Biochem Eng J 3:121-129

24. Papagianni M (2004) Fungal morphology and metabolite production in submerged mycelial processes. Biotechnol Adv 22:189-259

25. Amanullah A, Christensen LH, Hansen K, Nienow AW, Thomas CR (2002) Dependence of morphology on agitation intensity in fed-batch cultures of Aspergillus oryzae and its implications for recombinant protein production. Biotechnol Bioeng 77:815-826
26. Grimm LH, Kelly S, Krull R, Hempel DC (2005) Morphology and productivity of filamentous fungi. Appl Microbiol Biotechnol 69:375-384

27. DuBois M, Gilles KA, Hamilton JK, Rebers PA, Smith F (1956) Colorimetric method for determination of sugars and related substances. Anal Chem 28:350-356

28. Panda T, Naidu GSN, Sinha J (1999) Multiresponse analysis of microbiological parameters affecting the production of pectolytic enzymes by Aspergillus niger: a statistical view. Process Biochem 35:187-195

29. Nelson N (1944) A photometric adaptation of the Somogyi method for the determination of glucose. J Biol Chem 153:375-380

30. Somogyi M (1952) Notes on sugar determination. J Biol Chem 195:19-23

31. Gogus N, Taze BH, Demir H, Tari C, Unluturk S, Lahore MF (2014) Evaluation of orange peel, an industrial waste, for the production of Aspergillus sojae polygalacturonase considering both morphology and rheology effects. Turk J Biol 38:537-548

32. Oncul S, Tari C, Unluturk S (2007) Effect of various process parameters on morphology, rheology, and polygalacturonase production by Aspergillus sojae in a batch bioreactor. Biotechnol Prog 23:836-845

33. Nighojkar S, Phanse Y, Sinha D, Nighojkar A, Kumar A (2006) Production of polygalacturonase by immobilized cells of Aspergillus niger using orange peel as inducer. Process Biochem 41:1136-1140

34. Teixeira MFS, Lima JL, Duran N (2000) Carbon sources effect on pectinase production from Aspergillus japonicus 586. Braz J Microbiol 31:286-290

35. Galiotou-Panayotou M, Rodis P, Kapantai M (1993) Enhanced polygalacturonase production by Aspergillus niger NRRL-364 grown on supplemented citrus pectin. Lett Appl Microbiol $17: 145-148$

36. Grohmann K, Cameron RG, Buslig BS (1995) Fractionation and pretreatment of orange peel by dilute acid hydrolysis. Bioresour Technol 54:129-141

37. Talebnia F, Pourbafrani M, Lundin M, Taherzadeh MJ (2008) Optimization study of citrus waste saccharification by dilute-acid hydrolysis. Bioresources 3:108-122

38. Widmer W, Zhou WY, Grohmann K (2010) Pretreatment effects on orange processing waste for making ethanol by simultaneous saccharification and fermentation. Bioresour Technol 101:52425249

39. Buyukkileci AO, Hamamci H, Yucel M (2006) Lactate and ethanol productions by Rhizopus oryzae ATCC 9363 and activities of related pyruvate branch point enzymes. J Biosci Bioeng 102:464-466

40. Papagianni M, Moo-Young M (2002) Protease secretion in glucoamylase producer Aspergillus niger cultures: fungal morphology and inoculum effects. Process Biochem 37:1271-1278

41. Friedrich J, Cimerman A, Steiner W (1990) Production of pectolytic enzymes by Aspergillus niger-effect of inoculum size and potassium hexacyanoferrate II-trihydrate. Appl Microbiol Biotechnol 33:377-381

42. Hermersdorfer $\mathrm{H}$, Leuchtenberger A, Wardsack C, Ruttloff $\mathrm{H}$ (1987) Influence of culture conditions on mycelial structure and polygalacturonase synthesis of Aspergillus niger. J Basic Microbiol 27:309-315

43. Couri S, Pinto GAS, de Senna LF, Martelli HL (2003) Influence of metal ions on pellet morphology and polygalacturonase synthesis by Aspergillus niger 3T5B8. Braz J Microbiol 34:16-21

44. Malvessi E, da Silveira MM (2004) Influence of medium composition and $\mathrm{pH}$ on the production of polygalacturonases by Aspergillus oryzae. Braz Arch Biol Tecn 47:693-702 
45. Beg QK, Bhushan B, Kapoor M, Hoondal GS (2000) Effect of amino acids on production of xylanase and pectinase from Streptomyces sp QG-11-3. World J Microbiol Biotechnol 16:211-213

46. Hadj-Taieb N, Ayadi M, Trigui S, Bouabdallah F, Gargouri A (2002) Hyperproduction of pectinase activities by a fully constitutive mutant (CT1) of Penicillium occitanis. Enzyme Microb Technol 30:662-666

47. Villas-Boas SG, Esposito E, de Mendonca MM (2002) Novel lignocellulolytic ability of Candida utilis during solid-substrate cultivation on apple pomace. World J Microbiol Biotechnol 18:541-545

48. Nakkeeran E, Gowthaman MK, Umesh-Kumar S, Subramanian R (2012) Techno-economic analysis of processes for Aspergillus carbonarius polygalacturonase production. J Biosci Bioeng 113:634-640

49. Rangarajan V, Rajasekharan M, Ravichandran R, Sriganesh K, Vaitheeswaran V (2010) Pectinase production from orange peel extract and dried orange peel solid as substrates using Aspergillus niger. Int J Biotechnol Biochem 6:445-453

50. Pedrolli D, Gomes E, Monti R, Carmona E (2008) Studies on productivity and characterization of polygalacturonase from Aspergillus giganteus submerged culture using citrus pectin and orange waste. Appl Biochem Biotechnol 144:191-200 